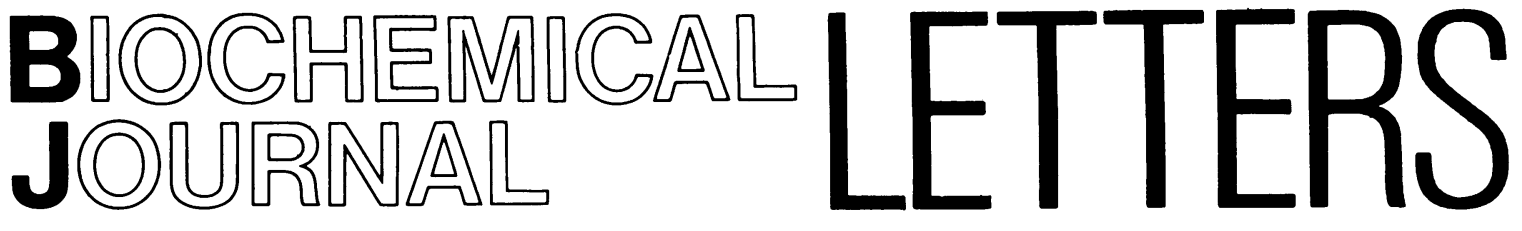

\section{Some comments on the relationship} between mammalian ferritins and the complex non-haem-iron-containing bacterial cytochromes $\boldsymbol{b}_{\mathbf{5 5 7 . 5}}$

Mammalian ferritin is an oligomeric protein containing a central non-haem iron core with the level of iron generally in the range $10-30 \%$ of the molecular mass. It is composed of 24 subunits, each of $M_{\mathrm{r}}$ approx. 20000. The physiological function of ferritin is to act as an iron storage protein, but the biochemical processes by which it takes up and releases iron are uncertain [see the reviews by Harrison et al. (1980) and Ford et al. (1984) and references therein]. Recently, similar proteins isolated from bacterial sources have been described (Stiefel \& Watt, 1979; Jiudi et al., 1980; Yariv et al., 1981; Chen \& Crichton, 1982). These have the common features of being oligomeric, with subunit $M_{\mathrm{r}}$ values in the range 15000-17000, and non-haem iron containing. The non-haem iron is contained in a central core, but the level of iron varies with the source of the protein and the culture growth conditions. Values in the range $13-20 \%$ of the molecular mass have been reported for the Azotobacter vinelandii protein (Stiefel \& Watt, 1979). These bacterial proteins have been named bacterioferritin, to emphasize the similarity with mammalian ferritin, but, unlike mammalian ferri- tin, the bacterial proteins all contain a cytochrome $b$ component. The presence of this component suggests that redox reactions play a role in iron uptake and release [see Ford et al. (1984) and references therein]. However, there is a dilemma: why does mammalian ferritin not contain a cytochrome? The purpose of this Letter is to present a hypothesis that might resolve this question and point the way towards elucidating some of the biochemical features of ferritin function.

The hypothesis is that mammalian ferritins have a cytochrome $b$ reaction partner within the cell that fulfils the function of the intrinsic cytochrome $b$ of the bacterial proteins. This suggestion is based on the following observations.

1. The optical spectral properties of the bacterial cytochrome $b$ closely resemble those of the eukaryotic cytochrome $b_{5}$ family of proteins (Table 1 ).

2. In mammalian systems, proteins of the cytochrome $b_{5}$ family are widely distributed and appear to be relatively non-specific redox reagents, since they function in a variety of processes. For example, they function in methaemoglobin reduction in red blood cells, cytochrome $P-450$ and fatty acid desaturase reduction in liver microsomes, and sulphite oxidation in mitochondria [see Guiard \& Lederer (1979); and Mathews (1985) and references therein]. Cytochrome $b_{5}$ is also located in the outer membrane of mitochondria, although its

Table 1. Haem optical spectra of cytochromes $b_{5}, b_{557.5}$ and $b_{1}$ Abbreviation used: n.d., not determined. The cytochromes $b_{556}$ and $b_{557.5}$ from $A$. vinelandii and $E$. coli are 'bacterioferritins' (Jiudi et al., 1980; Stiefel \& Watt, 1979; Yariv et al., 1981).

\begin{tabular}{|c|c|c|c|c|c|c|c|c|c|}
\hline \multirow[b]{3}{*}{ Cytochrome } & \multicolumn{4}{|c|}{$\lambda_{\text {max. }}(\mathrm{nm})$} & & & & & \multirow[b]{3}{*}{ Reference } \\
\hline & \multirow{2}{*}{$\begin{array}{c}\mathrm{Fe}(\mathrm{III}) \\
\gamma\end{array}$} & \multicolumn{3}{|c|}{$\mathrm{Fe}(\mathrm{II})$} & \multicolumn{4}{|c|}{ Absorbance ratios } & \\
\hline & & $\gamma$ & $\beta$ & $\alpha$ & $\gamma_{\text {red. }} / \gamma_{\text {ox. }}$ & $\gamma_{\text {red. }} / \beta_{\text {red. }}$ & $\gamma_{\text {red. }} / \alpha_{\text {red. }}$ & $\alpha_{\text {red. }} / \beta_{\text {red. }}$ & \\
\hline Liver microsomal $b_{5}$ & 413 & 423 & 528 & 557 & 1.45 & 9.78 & 6.57 & 1.51 & Lé \& Lederer (1983) \\
\hline $\begin{array}{l}\text { Mitochondrial outer } \\
\text { membrane } b_{5}\end{array}$ & 413 & 424 & 526 & 557 & 1.27 & n.d. & n.d. & n.d. & Nisimoto et al. (1977) \\
\hline $\begin{array}{l}\text { Neurospora crassa } \\
\text { nitrate reductase }\end{array}$ & 413 & 423 & 528 & 557 & 1.46 & 9.64 & 6.75 & 1.43 & Lé \& Lederer (1983) \\
\hline A. vinelandii $b_{556}$ & 414 & 422 & 526 & 556 & n.d. & n.d. & n.d. & n.d. & Jiudi et al. (1980) \\
\hline A. vinelandii $b_{557.5}$ & 417 & 425 & 527 & 557.5 & n.d. & n.d. & n.d. & n.d. & Stiefel \& Watt (1979) \\
\hline$E$. coli $b_{557.5}$ & 417 & 425 & 527 & 557 & 1.10 & 7.18 & 4.94 & 1.45 & Yariv et al. (1981) \\
\hline$E$. coli $b_{1}$ & 418 & 425 & 527.5 & 557.5 & 1.19 & 8.36 & 5.75 & 1.45 & Deeb \& Hager (1964) \\
\hline Rhodospirillum & 417 & 425 & 527 & 557.5 & 1.15 & 7.23 & 5.22 & 1.30 & Bartsch et al. (1971) \\
\hline
\end{tabular}

Vol. 227 
function here is not clear (Nisimoto et al., 1977). In fungi, cytochrome $b_{5}$ is part of lactate dehydrogenase and nitrate reductase (Guiard \& Lederer, 1979; Lé \& Lederer, 1983).

3. Liver microsomes contain a large amount of ferritin; e.g. as much as $70 \%$ of the iron contained by normal rat liver microsomes is in ferritin (Montgomery et al., 1974). Thus the cytochrome $b_{5}$-ferritin system here may be functionally analogous to the bacterial proteins. This is consistent with the work of Lee \& Richter (1977) who have shown that, in vitro, ferritin assembly and iron uptake in rat hepatoma cells takes place on the smooth endoplasmic reticulum. In this respect the proposed identity of Escherichia coli cytochrome $b_{557.5}$ with cytochrome $b_{1}$ (Stiefel \& Watt, 1979; Yariv, 1983) is relevant because cytochrome $b_{1}$ has been shown to be a membrane-associated protein (Deeb \& Hager, 1964). Liver microsomal cytochrome $b_{5}$ is also associated with the membrane.

The proposed similarity between cytochrome $b_{5}$ and cytochrome $b_{557.5}$ is not exact. Haem optical spectra are not good protein conformational probes because the most important influences on them are the nature of the haem itself, its ligands and its immediate environment. Therefore it is striking that all the mammalian and fungal cytochromes $b_{5}$ show a marked sequence and structural homology (Guiard \& Lederer, 1979); they all possess the cytochrome $b_{5}$ tertiary fold, which is very different from the $\alpha$-helical bundle structure of ferritin (Ford et al., 1984; Mathews, $1985)$. Since the cytochromes $b_{557.5}$ have a similar oligomeric structure, in terms of size and symmetry, to that of mammalian ferritin (Stiefel \& Watt, 1979; Yariv et al., 1981; Ford et al., 1984), it is difficult to see how they could contain a subunit with the cytochrome $b_{5}$ tertiary structure. An alternative explanation is that the bacterial proteins are composed of subunits which are $\alpha$-helical bundles in which haem is held in an environment resembling that of cytochrome $b_{5}$. In this respect it may be relevant that many bacteria contain monomeric and dimeric cytochromes $b$ and $c$ which have similar $\alpha$-helical bundle structures to that of ferritin [see Mathews (1985) and references therein] although none of those currently known has a cytochrome $b_{5}$-like optical spectrum or haem environment.

I thank Dr. J. V. Bannister and Professors P. M. Harrison and R. J. P. Williams for helpful discussion, and the Science and Engineering Research Council for an Advanced Fellowship.

\section{Geoffrey R. MOORE}

Inorganic Chemistry Laboratory, University of $O x$ ford, South Parks Road, Oxford OX1 3QR, U.K.

\section{(Received 7 January 1985)}

Bartsch, R. G., Kakuno, T., Horio, T. \& Kamen, M. D. (1971) J. Biol. Chem. 246, 4489-4496

Chen, M. \& Crichton, R. R. (1982) Biochim. Biophys. Acta 707, 1-6

Deeb, S. S. \& Hager, L. P. (1964) J. Biol. Chem. 239, 1024-1031

Ford, G. C., Harrison, P. M., Rice, D. W., Smith, J. M. A., Treffry, A., White, J. L. \& Yariv, J. (1984) Philos. Trans. R. Soc. London Ser. B. 304, 551-556

Guiard, B. \& Lederer, F. (1979) J. Mol. Biol. 135, 639650

Harrison, P. M., Clegg, G. A. \& May, K. (1980) in Iron in Biochemistry and Medicine II (Jacobs, A. \& Worwood, M., eds.), pp. 131-171, Academic Press, New York

Jiudi, L., Jiwen, W., Zepu, Z., Ya, T. \& Bei, D. (1980) Sci. Sin. Engl. Ed. 23, 897-904

Lé, K. H. D. \& Lederer, F. (1983) EMBO J. 2, 1909-1914

Lee, S. S. C. \& Richter, G. W: (1977) in Proteins of Iron Metabolism (Brown, E. B., Aisen, P., Fielding, J. \& Crichton, R. R., eds.), pp. 91-98, Grune and Stratton Mathews, F. S. (1985) Prog. Biophys. Mol. Biol. 45, 1-56

Montgomery, M. R., Clark, C. \& Holtzman, J. L. (1974) Arch. Biochem. Biophys. 160, 113-118

Nisimoto, Y., Takeuchi, F. \& Shibata, Y. (1977) J. Biochem. (Tokyo) 82, 1257-1266

Stiefel, E. I. \& Watt, G. D. (1979) Nature (London) 279, 81-83

Yariv, J. (1983) Biochem. J. 211, 527

Yariv, J., Kalb, A. J., Sperling, R., Bauminger, E. R., Cohen, S. G. \& Ofer, S. (1981) Biochem. J. 197, 171175 